\title{
The Different Type of MPPT Techniques for Photovoltaic System
}

\author{
Apar Chitransh, Sachin Kumar
}

\begin{abstract}
: we know that sun is the only sources which is available free of cost in our environment for the PV module. when the sun strikes in to the PV cell it converts to the electrical energy. Now a days to fulfill the requirement of energy the solar energy plays a main role of that. But some time this solar energy is not sufficient to fulfill this requirement than some time we use the MPPT techniques which is increase the power generation and main advantage of this techniques is that this is work in any climate. The full form of MPPT is MAXIMUM POWER POINT TRACKER. It gets the maximum power from the available $P V$ unit and it is not depending upon the any environmental conditions. In this paper we discuss in detail the several abilities that how they get the maximum power point and system convergence, efficiency and cost of implementation. In this paper we show that all type pf MPPT techniques.
\end{abstract}

Keyword: Photovoltaic System PV, MPPT, DC-DC Converter, Micro-Grid, and Mppt Techniques.

\section{INTRODUCTION}

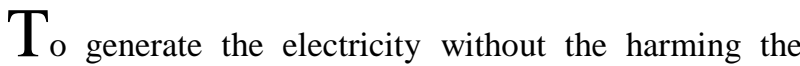
environment, the renewable energy is the best source which is a goof tendency in the market. And due to increasing the electricity demand the solar energy demand is also increased in market. But most of the best disadvantage is that the efficiency of the solar panel is very poor compete with the other energy generation system. Most of the research found that solar panels efficiency is approximately $30 \%$ to convert sunlight in to energy. Other side to implemented the other controller and device to improve the efficiency of that it may be costly but we design a MPPT technique which is utilize the solar panel to maximum potential. Mostly cases show that the MPPT compensate when the change comes in to the voltage and current characteristics of solar panel. MPPT allow to the battery to take more power as the form of voltage and current. As like many algorithms takes place for tracking the maximum power point of PV generator but this algorithm is most effective and has goof convergence speed and have more sensors and. In this paper we discuss about the different type of MPPT techniques 1.P\&O method 2. IC method 3. Fuzzy controller method.

Manuscript received on 25 September 2021 | Revised Manuscript received on 28 October 2021 | Manuscript Accepted on 15 November 2021 | Manuscript published on 30 November 2021.

* Correspondence Author

Apar Chitransh*, M.E. Electrical, Department of Electrical Engineering, Chandigarh University, Punjab, India

Mr. Sachin Kumar, Assistant Professor, Department of Electrical Engineering, Chandigarh University, Punjab, India

(c) The Authors. Published by Lattice Science Publication (LSP). This is an open access article under the CC-BY-NC-ND license (http://creativecommons.org/licenses/by-nc-nd/4.0/)

\section{MPPT (maximum power point tracker): -}

Some time it called the just power point tracking and basically its use in wind and PV solar system to maximize the power in different environment. Yes, mostly it shows with the solar power system to increase the power due to most of area the climate change suddenly. Basically, MPPT is a type of algorithm which include the controller for maximize the power from PV system. That voltage which the PV solar system can produce the maximum voltage that called the maximum power point or peak power voltage also. in hot day or sunny day, the PV solar cell temperature down to the approximate $15 \mathrm{v}$ with the help of MPPT it can be increase with the $18 \mathrm{~V}$ on a very cold day. The working principle of MPPT is that it connected too the PV system and it see the best power output of PV module and connected battery which power out put is better it converts that and get the maximum current to the battery. Also, it helps to supply the DC load, which is connected to the directly to the battery.

\section{Description of PV Generator: -}

the equivalent circuit of the solar cell is shown in to the fig. in this figure it consists the series resistance, light generated current source and parallel resistance.

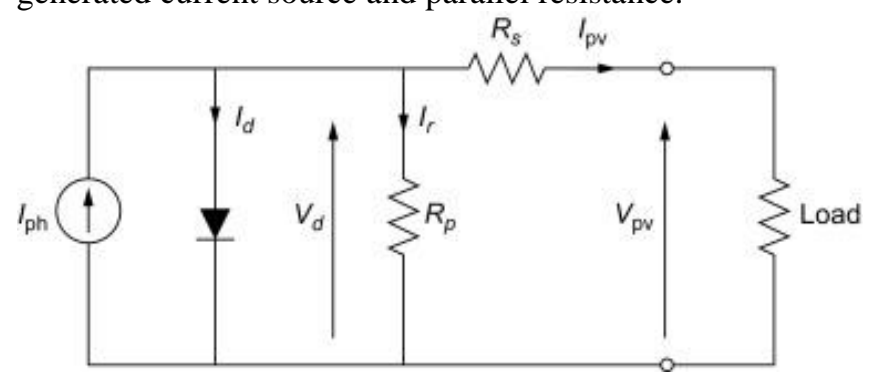

Fig: 1.equivalent circuit of photovoltaic cell

$$
I=I_{p h}-I_{\text {sat }} \cdot\left[\exp \left(\frac{q \cdot\left(V+R_{s} \cdot I\right)}{n k t}\right)-1\right]-\frac{V+R_{s} \cdot I}{R_{s h}}
$$

Here $\mathrm{I}=$ denotes the solar array current, $\mathrm{V}=$ denotes the output voltage,

Iph $=$ denotes the light generated current

Isat $=$ shows the reverse saturation current

$\mathrm{Q}=$ electronic charge which is $1.6^{*} 10^{-19} \mathrm{C}$

$\mathrm{N}$ is the deviation factor; $\mathrm{K}$ is the Boltzmann constant which is standard value is 1.3807 .

Rs denotes the series resistance which is connected to the series with the load.

In various cases it seen that the output characteristics of $\mathrm{PV}$ array is nonlinear and due to the temperature and load condition it may be affected.

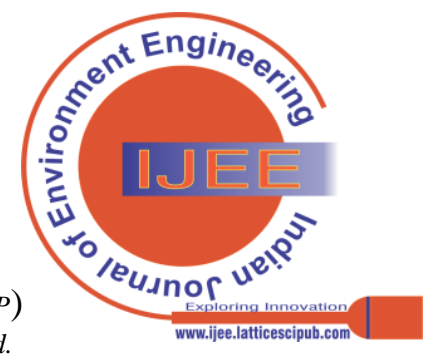




\section{Boost type DC-Dc Converter: -}

Mostly this type of converter consists of the MOSFET, boost inductor and filter capacity and output diode and load resistor. According to the fig., when the switch $\mathrm{K}$ is the on mode then the boost inductor increases and the diode goes to the off mode. When the $\mathrm{K}$ is off mode that the all collecting power goes to the stored in to the present inductor and which is released through the diode. The pulsing current which is produced by the switching action like On and Off mode is gone smoothed by the help of presenting capacitive filter in to the circuit and dc voltage provided the load. The present transfer function is obtained by the considering the steady state operation and also dc voltage transfer function.

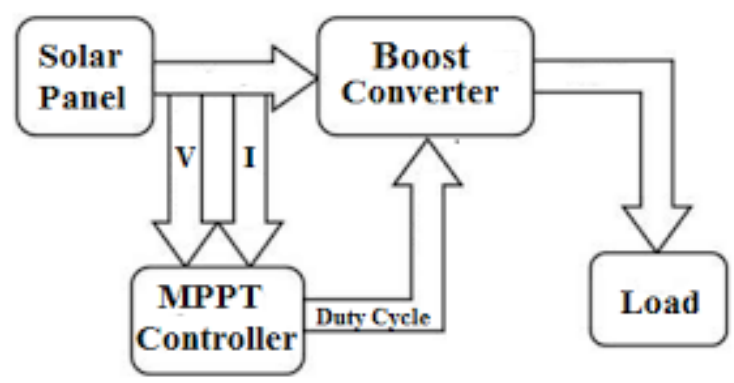

Fig: 2.block diagram of MPPT boost converter

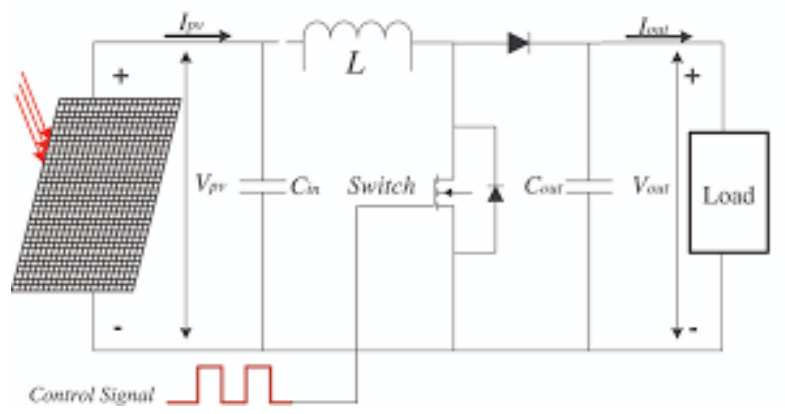

Fig: 3. equivalent circuit of MPPT boost converter

$$
M(\delta)=\frac{V_{0}}{V_{i}}=\frac{-\delta}{1-\delta}
$$

\section{Microgrid of PV System: -}

With the definition of microgrid is a group of interconnected load and distributed energy which is also attached with the any centralized grid and disconnect from the grid. The grid connected microgrid also give the economic benefit, increase the demand of electricity and generation also. microgrid also helpful to integrated with the renewable energy sources. To add the PV added to the microgrid which is help full to delivering the clean and costeffective electricity. When the solar system generates the source. microgrid helpful to provide the supply with the localized when the grid is down. When we design the PV project, consider that the microgrid is the future of the generating unit. That micro-grid includes the generators and other renewable energy and energy storage system. For some time, it uses the master inverter to set the frequency and voltage in the absence of the isochronous generator.

\section{Different Type of MPPT Techniques: -}

We know that MPPT depends upon the array temperature and solar irradiation incase of PV system generate the power, so MPPT track the solar array. In this section we study about the 4 different type of techniques coming in to the picture.

\section{Perturb and Observe Method: -}

$\mathrm{P} \& \mathrm{O}$ is used for tracking the MPP. This technique is tracking the MPP of PV system in mirror scale due to the variation of power of PV module. The output power can be measured with the previous output power for comparing and the output power is measured in periodically. Some time when the power increases the same process is continued otherwise the $\mathrm{P} \& \mathrm{O}$ can be gone in reversed. $\mathrm{PV}$ module is depending on the voltage and current when it increases or decreased the power is also increased and decrease. The algorithm of the P\&O is forced to the MPP to get the maximum power outcome and increasing and decreasing the $\mathrm{PV}$ outcome. The change in direction of P\&O method id depend upon the PV voltage increase and decrease concept when the voltage increased then the $P \& O$ goes to the same direction and when the voltage is decreased the $\mathrm{P} \& \mathrm{O}$ goes to the reverse direction. And this process gives the output in periodically form. The duty cycle perturbation at time $(\mathrm{t}+\mathrm{l})$ can be decided on the basic of the following relationship:

$$
d(t+1)=d(t)+(2 \operatorname{sign}-1) D
$$

Where sign is given by:

$$
\text { sign }=([P(t)-p(t-1)]>0) \oplus([V(t)-V(t-1)]
$$

The oscillation around the MPP can be minimized by reducing the perturbation step size D.

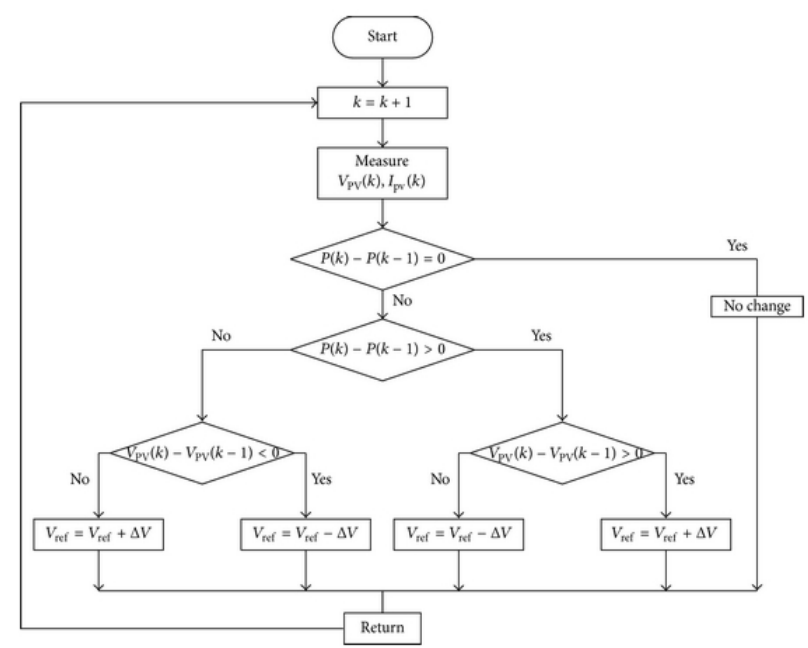

Fig:4 flow chart of $P \& O$ algorithm

Incremental Conductance Method: -

A typical solar panel convert $30-40 \%$ solar radiation in to the electrical energy. MPP is improve the efficiency of solar power system. According to the maximum power transfer the power output is maximum when the impedance of the circuit matches with the load impedance. IC method is used for determine the operating point for the information voltage and current source. This method is also based on the slope of the solar power curve versus the voltage curve at zero MPP. The most relationship between the instantaneous conductance and incremental conductance is

$$
\frac{\Delta I}{\Delta V}+\frac{I}{V}=0 \quad A T M P P
$$

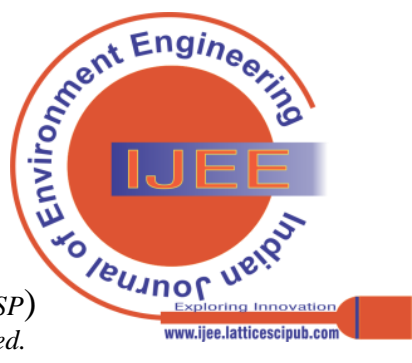




$$
\begin{aligned}
& \frac{\Delta I}{\Delta V}+\frac{I}{V}>0 \\
& \frac{\Delta I}{\Delta V}+\frac{I}{V}<0
\end{aligned}
$$

The amplitude of the MPP is controller with the help of $€$. As this increase the MPP is decrease. Due to some noise around the system the measurement fault will occur and the above equation will be satisfied. in steady state condition the system oscillated near by the MPP. To improve the performance of the MPP the value of the $€$ is chosen very carefully.

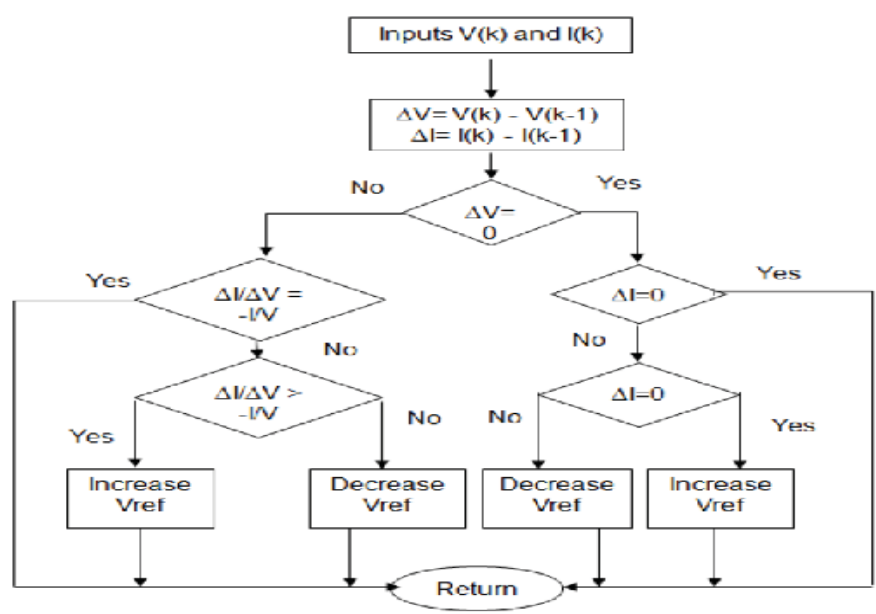

Fig:5 flow chart of incremental conductance algorithm

\section{Current Measurement Method: -}

This method requires the both current and voltage for measurement the MPP. For this method algorithm we need only the PV current value for the PV module. For this method we use the DC-DC boost converter between the PV panel and battery where the energy can be stored. the most work of this MPP is that it can received the maximum value of output else it is from the PV module and it is from battery. The energy conversion principle allows to this method.

$$
P_{i n}=V_{p v} I_{p v}=V_{b a t} I_{b a t}
$$

Where Pin is the available power in PV module and V bat is the available voltage in battery.

$$
\begin{gathered}
I_{o u t}=\frac{-(1-\delta)}{\delta} I_{p v} \\
V_{p v} I_{p v}=-V_{b a t} \frac{-(1-\delta)}{\delta} I_{p v} \\
P^{*}=\frac{(1-\delta)}{\delta} I_{p v}
\end{gathered}
$$

In some cases, it shows that when the $\mathrm{P}^{*}$ is maximum then the $\mathrm{P} \& \mathrm{O}$ algorithm is used due to it tracks the maximum power output from the PV system in different climate.

\section{Fuzzy Logic Controller Method: -}

It based on the microcontroller devices application due to its better result it considers in MPPT techniques. It works depend upon the fuzzy logic, provide a mathematical tool for determine the power tracking. When we applied the input on MPP then some type of error come in to the picture and also charge of error comes....

$$
\begin{aligned}
& E(k)=\frac{P(k)-P(k-1)}{V(k)-V(k-1)} \\
& C(E)=E(k)-E(k-1)
\end{aligned}
$$

Where the $\mathrm{P}(\mathrm{k})$ and $\mathrm{V}(\mathrm{k})$ is denotes the output power and voltage of PV panel gd D is the defuzzification while $\mathrm{dD}$ denotes the output of this. The fuzzy controller consists of three functional blocks like fuzzy rule and inference engine and finally defuzzification's.

\section{FUZZIFICATIONS}

it requires that used in the control rule which is set to the notation with standard logic. Each block which is include in the function of the FLC including the positive big, positive small, zero equivalent, negative small, negative big. This fuzzification complete in two cases

First case: $\mathrm{E}$ is positive and as I describe on the IC method when the MPP is going to the left. Then the charge of error is positive. Then the MPP is working mode and the $\mathrm{CE}$ is negative that goes to the inverse mode.

Second case: $\mathrm{E}$ is negative then the MPP is right side, that case the CE is positive and work on the away to the MPP and negative it work on vice versa.

\section{Defuzzification: -}

This process calculated the crisp output of the FLC. basically, it describes the space of fuzzy logic statement.

\section{CONCLUSION}

When we increase the power outcome, we applied the MPPT techniques. In this paper we discuss all 4 type of techniques and their working property. The $\mathrm{P} \& \mathrm{O}$ is very simple to modeling and carried out very easily. The main draw of this techniques is that in the time of steady state it oscillates around the MPPT. The oscillation around the MPP is depend upon the step size how much we increased the step size the MPP is done the fast tracking of PV module. There is trade off of dynamic ad steady performance. The major advantage of IC method that the sensors techniques it measures the only one variable and that is photovoltaic current. The FLC provide the better result for taking means it is faster than other MPPT method. So, it is clarified that MPPT is necessary to do with the PV module system to increase and improve the efficiency.

\section{REFERENCES}

1. Gergaud O, Multon B, Ben Ahmed H. Analysis and experimental validation of various photovoltaic system models. 7th International ELECTRIMACS Congress, Montréal, Canada, 2002, pp. 1-6.

2. Esram T, Chapman P.L. Comparison of photovoltaic array maximum power point tracking techniques. IEEE Trans. Energy Conversion, 2007; 22: 439-449. [CrossRef]

3. Tafticht T, Agbossou K, Doumbia ML, Chériti A. An improved maximum power point tracking method for photovoltaic systems. Renewable Energy, 2008; 33: 1508-1516. [CrossRef]

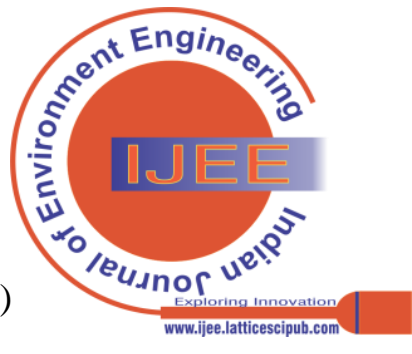


4. Veerachary M, Senjyu T, Uezato K. Neural-network-based maximum- power-point tracking of coupledinductor interleavedboostconverter-supplied PV system using fuzzy controller. IEEE Trans. Ind. Electron, 2003; 50: 749-758. [CrossRef]

5. Enrique JM, Duràn E, Sidrach-de-Cardona $\mathrm{M}$, Andùjar JM. Theoretical assessment of the maximum power point tracking efficiency of photovoltaic facilities with different converter topologies. Solar Energy,2007; 81: 31-38. [CrossRef]

6. Femia N, Petrone G, Spagnolo G, Vitelli M. Optimization of Perturb and Observe Maximum Power Point Tracking Method. IEEE Trans. Power Electron., 2005; 20: 963-973. [CrossRef]

7. Youngseok J, Junghun S, Gwonjong $\mathrm{Y}$, Jaeho C. Improved Perturbation and Observation Method (IP\&O) of MPPT control for photovoltaic power systems. The $3^{\text {lst }}$ Photovoltaic Specialists Conference, Lake Buena Vista, Florida, USA, 2005, pp. 1788-1791.

8. Hussein KH, Mota I. Maximum photovoltaic power tracking: An algorithm for rapidly changing atmospheric conditions. in IEE Proc. Generation Transmiss. Distrib., 1995, pp. 59-64. [CrossRef]

9. Kobayashi K, Takano I, Sawada Y. A study on a two stage maximum power point tracking control of a photovoltaic system under partially shaded insolation conditions. in IEEE Power Eng. Soc. Gen. Meet., 2003, pp. 2612-2617.

10. Salas V, Olias E, Lazaro A, Barrado A. New algorithm using only one variable measurement applied to maximum power point tracker. Solar Energy Material and Solar Cells 87, 2005, pp. 675-684. [CrossRef]

\section{AUTHOR PROFILE}

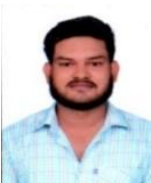

Apar Chitransh, is pursuing M.E. in electrical engineering in power system specialization in Chandigarh university. His area of interest in wind energy system and power electronics devices and power system, quantum computing. He published his work without copy right in various journals and preparing for join the conferences also. till now he published more than 5 papers in international journal regarding the energy consumption and wind energy related paper. Also, member of IEEE.

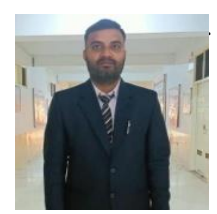

Sachin Kumar, received his Master's Degree in Electrical Engineering from NITTT Chandigarh. He is currently working as Assistant Professor in Electrical Engineering Department at UIE, Chandigarh University Gharuan Punjab. He is pursuing Phd. from Chandigarh University. He has teaching experience of 7.67 years. He is the author of 8 research paper published in journals/conference. His research interests include Power Electronics and Electrical Instrumentation.

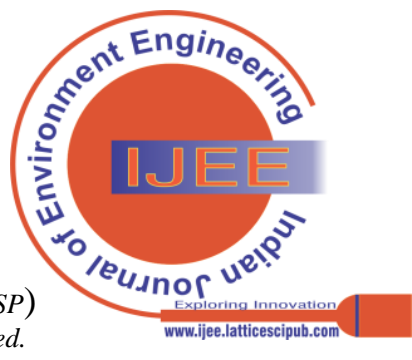

